\title{
Formação Gerencial: Pós-graduação Lato Sensu e o Papel das Comunidades de Prática
}

\author{
Cláudia Simone Antonello \\ Roberto Ruas
}

\begin{abstract}
Resumo
O artigo pretende repensar a questão da formação gerencial e, neste sentido, destaca dois aspectos que estão estreitamente vinculados a esta temática: a) analisa a perspectiva da abordagem aprendizagem na ação nos cursos de formação gerencial de longa duração; b) introduz uma discussão acerca das alternativas para superar as dificuldades referentes à efetividade desses cursos na perspectiva de resposta às problemáticas empresariais. A partir destes objetivos, o artigo examina as possibilidades dos processos de Aprendizagem na Ação em cursos de pósgraduação lato sensu como forma de articulação entre informação teórica e experiência pessoal/ profissional. Neste sentido, analisa a questão da estratégia de aprendizagem e reflete sobre o fato de ela ser tão ou mais importante que os conteúdos específicos das disciplinas e seminários, pelo menos no que se refere ao desenvolvimento de certo tipo de competências. Resulta em propor e discutir uma concepção que visa estabelecer conexões mais sistemáticas entre a modalidade de curso analisada e o processo de desenvolvimento de competências. Essa concepção é baseada na emergência de novos paradigmas no campo da aprendizagem e formação gerencial, cujos fundamentos se concentram na abordagem Aprendizagem na Ação, com destaque para a noção de Comunidades de Prática nas organizações.
\end{abstract}

Palavras-chave:aprendizagem organizacional; formação gerencial; desenvolvimento de competências; aprendizagem na ação; comunidades de prática.

\section{Abstract}

The article intends to rethink the managerial formation subject, and highlights, two narrowly linked aspects it this theme: a) it analyzes the use of the Learning in the Action approach in long duration managerial formation courses; b) it introduces a debate concerning the alternatives to overcome the difficulties regarding the effectiveness of those courses in solving business problems. From these objectives, the article examines the possibilities for using Learning in the Action processes in post-graduation Lato Sensu courses (as MBA's) as a way to connect theoretical information and personal/professional experience. In this sense, it analyzes the subject of the learning strategy to be so or more important than the specific contents of the disciplines and seminars, at least in what refers to the development of certain types of competences. Finally, it proposes a conception that seeks to establish more systematic connections among the analyzed courses and the competences development process. That conception is based on the emergency of new paradigms in the field of learning and managerial formation whose foundations concentrate on the Learning in the Action approach, with prominence for the notion of Communities of Practice in the organizations.

Key words: organizational learning; managerial education; managerial competences; learning in the action; communities of practice. 


\section{Notas Introdutórias: Formação Gerencial}

De acordo com Liedtka et al. (1999) e Raelin (1998),as empresas gastam anualmente alguns bilhões de dólares em formação gerencial. Com a competição e a mudança cada vez mais aceleradas, as demandas acerca das responsabilidades gerenciais crescem e este investimento em educação tende a aumentar, à medida que as organizações passarem a enxergar nas experiências de desenvolvimento em sala de aula uma alternativa de desenvolvimento das competências dos gestores. Contudo há grande incerteza acerca do retorno destes investimentos, especialmente no que concerne à apropriação na atividade profissional do que é aprendido em sala de aula, bem como em termos de sustentação e repercussões das experiências em educação executiva de curta duração.

Ainda conforme estes autores, pode-se identificar uma tendência evidente no campo da formação gerencial: são os programas in company ${ }^{(1)}$. Desta perspectiva, Doyle (1994, p. 7) comenta que a educação executiva pode ser vista como ferramenta estratégica, pois há “a necessidade urgente do desenvolvimento de executivos, a fim de promover aprendizagem individual, adaptação organizacional e renovação”.

Examinando a literatura que trata de formação gerencial, podemos encontrar um debate acerca das vantagens desta abordagem (BOLT, 1993; HEQUET, 1992; MCCLENAHEN, 1996), bem como discussões detalhadas do progresso e possibilidades representadas pelas parcerias entre empresas e universidades (GHOSHAL et al., 1992; LORANGE, 1994). Este debate tem focalizado mais as características dos investimentos em formação gerencial: como e para onde (VICERE; WHITE, 1994), e também, sobre os tipos de oferta neste campo dentro dos programas universitários (BUSINESS WEEK, 1994; THE JOURNAL OF BUSINESS STRATEGY, 1996). Entretanto a revisão da literatura acerca dessas questões decepciona pela carência de trabalhos empíricos que avaliem a efetividade da formação gerencial.

Embora sejam inúmeros os relatórios do impacto de programas deste tipo (ELLER, 1995; RIFKEN, 1996), são muito raros aqueles que aportam dados quantitativos. Segundo Tannenbaum e Woods (1992, p. 64), as empresas não investem na mensuração dos resultados de treinamento da mesma forma que para avaliar a eficiência e efetividade de suas vendas e produção. No entanto os investimentos em treinamento e desenvolvimento continuam sendo feitos sem considerar uma avaliação sistemática. 
Dionne (1996) afirma que os problemas mais significativos que desafiam os pesquisadores e profissionais de Recursos Humanos é a falta de referências norteadoras e uma metodologia para mensuração e avaliação. Além disso, constata-se outro problema: trata-se das abordagens e metodologias empregadas nos referidos cursos.

As metodologias e abordagens empregadas nos programas de pós-graduação lato sensu (especialização) estariam distantes da problemática empresarial, aparentemente não atendendo às demandas em formação gerencial, em função da complexidade do atual ambiente de negócios. Por outro lado, mais recentemente os programas de formação convencionais têm procurado inserir inovações, tais como experiências e simulações em sala de aula ou laboratórios, mas estas ainda estão "distantes de uma perspectiva de desenvolvimento de competências" (RUAS, 2001a). Concomitantemente, a crítica empresarial volta-se para o distanciamento dessas metodologias das especificidades do ambiente organizacional. Há uma dificuldade no processo de transferência e adaptação dos resultados da formação no ambiente de trabalho pelos participantes destes cursos. Ou seja,

"Na maioria dos casos, os participantes destes programas, não conseguem, de maneira isolada e sem um apoio metodológico específico, apropriar em suas atividades as enormes potencialidades geradas entre os conteúdos, exercícios e dinâmicas tratados no ambiente de treinamento” (RUAS, 2001b).

Uma das alternativas para enfrentar esta problemática seria através do conceito da aprendizagem na ação (LIEDTKA et al., 1999). A origem da idéia de aprender na ação pode ser localizada pelo desenvolvimento da perspectiva de Kurt Lewin de pesquisa-ação, onde o conhecimento é produzido na ação. Raelin (1997, p. 21) descreve isto como uma abordagem de desenvolvimento postulada na noção de que "as pessoas aprendem efetivamente ao trabalharem problemas em tempo real, em seus próprios locais de trabalho”.

Esta noção foi inicialmente desenvolvida por Revans (1971), quando ele diferenciou o 'conhecimento tradicionalmente programado' (ensino em sala de aula por conferência) do 'insight por questionamento', baseado nas próprias experiências dos participantes e obtido pela reflexão e discussão com um grupo de especialistas da mesma área. Mais especificamente, aprendizagem na ação foi vista utilizando-se dos problemas organizacionais reais, trabalhando em equipes de gerentes, com executivos que concordavam em escutar e responder às soluções propostas (LEWIS; MARCH, 1987). Esta abordagem foi caracterizada como "a escolha de desenvolvimento executivo para os anos noventa" (KEYS, 1994).

Liedtka et al. (1999) em seus estudos concluíram que a formação gerencial 
desenvolvida no âmbito universitário pode ser um investimento de longo prazo. Neste sentido, os cursos ao serem projetados e estruturados incorporando um modelo de aprendizagem na ação, tem impacto mais intenso e duradouro na vida profissional de egressos. Verificaram também um desenvolvimento de competências maior entre os egressos desses programas em relação seus pares de trabalho que não haviam participado dos cursos.

Assim, duas das problemáticas e críticas mais frequentes parecem ser ainda recorrentes: a) a distância entre as metodologias e abordagens empregadas nos programas de formação gerencial convencionais (em sala de aula), em face do que se pode chamar de problemática empresarial; b) o gap entre a formação propriamente dita e sua adaptação no ambiente de trabalho.

Partindo desse contexto, o artigo pretende repensar a questão da formação gerencial e para isso seleciona a abordagem da aprendizagem na ação como alternativa para enfrentar os desafios acima abordados. Neste sentido, destaca dois aspectos que estão estreitamente vinculados ao tema: a) analisa a perspectiva da aprendizagem na ação neste tipo de curso de formação gerencial; b) introduz uma discussão acerca das alternativas para superar as dificuldades referentes à efetividade dos cursos regulares de formação gerencial.

\section{Reflexões Sobre Estratégias de Aprendizagem Empregadas na Formação Gerencial}

De acordo com Burgoyne e Stuart (1991), enquanto os programas de desenvolvimento gerencial utilizam diversas estratégias de aprendizagem formalizadas, acredita-se que conferências, jogos e simulações, projetos, estudos de caso, vivências, leituras guiadas, role playing, seminários, instrução programada possam apresentar resultados promissores em sua utilização. Estas estratégias de aprendizagem provocam uma articulação quase lúdica, mas sistemática, entre teoria e prática e acabam por construir oportunidades muito ricas de construção e desenvolvimento de competências gerenciais.

As abordagens formalizadas apresentam várias negligências; em particular sua natureza abstrata e artificial, que não consegue compensar e/ou atingir a realidade dos procedimentos gerenciais com suas problemáticas e temas cotidianos (BURGOYNE; STUART, 1991), pois o foco da abordagem formal se coloca basicamente na entrega de uma ampla gama de conhecimento (conceitual) e habilidades nos vários campos e disciplinas funcionais de administração. 
Raelin (1997) entende que, além da instrução em sala de aula, outro modo importante de desenvolvimento gerencial ocorre pela experiência. As trocas, as vivências através de exercícios práticos, simulações e jogos possibilitam a experiência e a socialização e compartilhamento de conhecimento. Revela também que as dinâmicas e atividades que ensejam mais proximidade entre conteúdos teóricos, por um lado, e o contexto das atividades profissionais dos participantes, por outro, resultam geralmente em melhores condições para formação de competências gerenciais. A aproximação dos conteúdos teóricos de contextos e atividades profissionais específicas e reais gera um ambiente mais propício à formação de competências gerenciais efetivas.

Em muitos casos, infelizmente, sala de aula e experiências de desenvolvimento no mundo real são vistos como dimensões tipicamente independentes do universo gerencial. É como se não houvesse necessidade de associar teoria e prática. Em contrapartida, a aprendizagem baseada na ação funde deliberadamente a teoria com a prática e reconhece a interseção de formas explícitas e tácitas de saber em níveis individuais e coletivos. Reconhece que a aprendizagem é adquirida por meio da prática e pode acontecer enquanto se trabalha, através das tarefas ou de relações.

Nesta perspectiva constata-se que a estratégia de aprendizagem parece ser tão ou mais importante que os conteúdos específicos das disciplinas e seminários, pelo menos no que se refere ao desenvolvimento de certo tipo de competências. Por exemplo, no caso dos cursos in company, as estratégias de aprendizagem e os recursos didáticos empregados poderiam voltar-se para a troca de idéias, instigar a visão sistêmica da organização e o estabelecimento de associação de experiências dos participantes à teoria e vice-versa.

Da mesma forma, se acreditarmos que conhecimento é algo que é armazenado, seja na biblioteca ou no cérebro (WENGER; LAVE, 2000), então teria sentido compactá-lo e apresentá-lo de modo sucinto e articulado aos estudantes. Porém, se conhecimento é visto como surgindo de uma participação ativa no aparato de nossa vida cotidiana e de trabalho, e é isso que a literatura sobre o tema revela, então teríamos que ampliar o formato convencional da sala de aula e, realmente, interpretar o local de trabalho como lugar que enseja o ato de aprender. Isso remete a outra idéia:

"Em lugar de enfatizar habilidades técnicas, a aprendizagem na ação concentrase no desenvolvimento de comportamentos fundamentais de liderança e aprender a aprender através de atividades. Se nossos gerentes realmente são visivelmente míopes por causa de sua perspectiva demasiadamente técnica ao resolver problemas organizacionais, a aprendizagem na ação pode merecer um olhar mais profundo e atento" (RAELIN, 1993). 
Outra dificuldade parece ser a articulação entre cultura-expectativas acadêmicas e cultura-expectativas gerenciais. E essas dificuldades se desdobram tanto no processo de transferência e aplicação do conhecimento para a realidade do ambiente de trabalho (RUAS, 2001a), quanto na oportunidade e seleção das disciplinas empregadas nestes programas em face das demandas do ambiente empresarial. Sem esquecer, é claro, os métodos pedagógicos.

Por outro lado, um curso in company poderia atender algumas das expectativas da empresa e dos participantes, à medida que, além de disciplinas específicas, desenvolvesse exercícios progressivos para discussão da forma de gestão, estratégias e processos da organização. Aproximar os conteúdos teóricos do contexto das atividades profissionais pode resultar em maior consistência na formação de competências gerenciais, o que seria decisivo nos processos de aprendizagem.

Reforçando este posicionamento, a literatura enfatiza atualmente perspectivas sistêmicas e integradas no desenvolvimento gerencial. Tais visões defendem políticas, abordagens e práticas que localizam a formação gerencial dentro de seu amplo contexto técnico, social, político e cultural, e reconhecem o papel de ambos os fatores, o individual e organizacional. A visão que prevalece é a de que objetivos e atividades do desenvolvimento gerencial precisam estar fundamentados numa estratégia organizacional, ajustados a uma estrutura organizacional, e flexíveis o bastante para mudarem com a organização e com o próprio desenvolvimento gerencial.

Após estas reflexões e com base na abordagem Aprendizagem na Ação, destacamos uma de suas formas mais referenciadas, mas ao mesmo tempo menos conhecida em termos de suas peculiaridades e dinâmica: as Comunidades de Práticas (CoPs), que passa a ser apresentada a seguir.

\title{
Teias de Participação e Competências Gerenciais: Desvendando a Aprendizagem Informal e as Comunidades de Prática
}

\begin{abstract}
"Acontece, porém, que a toda compreensão de algo corresponde, cedo ou tarde, uma ação. Captado um desafio, compreendido, admitidas as hipóteses de resposta, o homem age. A natureza da ação corresponde à natureza da compreensão. Se a compreensão é crítica ou preponderantemente crítica, a ação também o será. Se é mágica a compreensão, mágica será ação”. Paulo Freire.
\end{abstract}

No campo da aprendizagem na ação uma das abordagens mais ricas é a que trata da aprendizagem informal e das comunidades de prática. 
A aprendizagem informal acontece naturalmente como parte de trabalho diário, como troca de críticas à efetividade no atingimento das metas e gera um ambiente estimulante, desafiador e de desenvolvimento para todos os seus funcionários. Usualmente os eventos de treinamento são considerados espaços típicos de aprendizagem e desenvolvimento profissional.

Os benefícios mais sustentáveis, em termos de necessidades individuais e organizacionais (LAVE; WENGER, 1991; REVANS, 1982), tendem a ser o resultado da ação ou a aprendizagem situada ${ }^{(2)}$, que é informal, e resulta diretamente de atividades relacionadas com o trabalho. Esta é a aprendizagem que se dá em espaços e interstícios de vida organizacional - no café ou durante uma saída de carro, em uma reunião em torno de uma piscina ou durante um processo de produção no chão de fábrica. É caracterizado por relação e interação interpessoal em processos sociais básicos como: 1) resolução de problemas formal e informal em grupos ou equipes; 2) cometendo-se erros; 3) refletindo-se na experiência e aplicando a aprendizagem em prática; 4) confrontando os gaps entre visão organizacional e a realidade; 5) lidando diretamente com conflito ou diferenças no local de trabalho; 6) participando de tomada de decisão organizacional; 7) preenchendo um vácuo de liderança; 8) aprendendo habilidades técnicas no trabalho a partir de colegas.

De acordo com Lankard (2000) a aprendizagem situada é uma das abordagens que é receptora de atenção no campo da aprendizagem de adultos e no local de trabalho. Nesta perspectiva aprende-se em contextos que refletem como o conhecimento será usado em situações da vida real. A estratégia está baseada na premissa de que conhecimento não é independente, mas fundamentalmente situado, sendo em parte um produto da atividade, contexto e cultura em que é desenvolvido (BROWN; DUGUID, 1992). Orey e Nelson (1994, p. 623) elaboram uma explicação:

“Aprendizagem requer mais que só pensamento e ação, ou uma situação física ou social particular física, ou de receber um corpo de conhecimento; também requer participação nas atuais práticas da cultura”.

Brown e Duguid (1992) descrevem este tipo de local de trabalho que aprende como um processo que acontece por teias de participação. Wenger e Lave (1998), e Wenger $(1996,1999)$ caracterizaram estas teias de aprendizagem informais como Comunidades de Prática (CoP), enquanto Boland e Tenkasi (1995) recorrem a elas como comunidades de saber. Ao invés de representar aprendizagem como o que acontece dentro de sistemas formais, por exemplo pelo treinamento em sala de aula ou uso de banco de dados, esta abordagem volta-se a para aprendizagem que acontece através da participação no trabalho. 
As organizações que encorajam, ou pelo menos não proíbem estas comunidades emergentes, reconhecem que esta transferência de conhecimento e aprendizagem mais integrada é facilitada através de uma autêntica interação social. Livingstone (1999, p. 3-4) sugere que aprendizagem informal seja alguma atividade que envolva a busca de entendimento, conhecimento ou habilidade que acontece fora dos currículos que constituem programas educacionais, cursos ou workshops.

Outra definição é oferecida por Watkins e Marsick (1992, p. 288) em que a aprendizagem informal pode ocorrer a partir de uma experiência formalmente estruturadas, com base em atividades específicas para este fim. Aprendizagem informal pode ser planejada ou não planejada, mas normalmente envolve algum grau de consciência que a pessoa está aprendendo. Os próprios autores dizem que aprendizagem informal pode encontrar-se em processos formais de ensino.

Na abordagem das questões de identificação e avaliação da aprendizagem informal, é crucial não esquecer a sua natureza contextual. Quando adquiridos em ambientes sociais e concretos, os conhecimentos e as competências são em grande parte o resultado da participação em comunidades de prática. Esta perspectiva implica valorizar não apenas o lado relacional (o papel do indivíduo dentro de um grupo social), mas também a qualidade da aprendizagem. Aprender, em termos individuais, significa adquirir competências de desempenho por envolvimento num processo contínuo de aprendizagem. Como tal, a aprendizagem não é apenas reprodução, mas também reformulação e renovação do conhecimento e das competências.

Os resultados dos processos de aprendizagem, que também representam o que alguns autores denominam competências são, em parte, de natureza tácita (POLANYI, 1983). Isso significa que é difícil verbalizar e delimitar os passos ou regras específicas, inerentes à determinada competência. Em alguns casos, as pessoas nem sequer estão conscientes de possuírem determinada competência. Este é um aspecto extremamente relevante para a tarefa de avaliação da aprendizagem informal, sobre o qual as metodologias terão de refletir. Muito do nosso saber-fazer foi adquirido pela prática e à nossa própria custa. Um marceneiro experiente sabe utilizar as ferramentas do seu ofício de uma forma que escapa à verbalização. Normalmente, consideramos este saber-fazer tão natural, que não percebemos em que medida ele permeia as nossas atividades (BJORNAVOLD, 2001).

De acordo com Schugurensky (2000) existem duas categorias, intencionalidade e consciência, e a partir delas é possível desenvolver uma taxionomia, identificando três tipos ou dimensões de aprendizagem informal, vide Quadro 1 a seguir. 


\section{Quadro 1: Três Dimensões da Aprendizagem Informal}

\begin{tabular}{|c|c|c|}
\hline Forma & Intencionalidade & $\begin{array}{c}\text { Consciência (na hora da aprender } \\
\text { experiência) }\end{array}$ \\
\hline Autodirecionada & Sim & Sim \\
\hline Incidental & Não & Sim \\
\hline Socialização & Sim & Não \\
\hline
\end{tabular}

Verifica-se, a partir do que foi comentado até aqui, a impossibilidade de dissociar a aprendizagem informal e na ação, das comunidades de prática. Assim, as comunidades de prática (Cops) são descritas como "um grupo interdependente de pessoas com conhecimento complementar e que interagem através de (recursos e outras) relações” (MERALI, 2000); são a resposta para os problemas identificados. Além disso, as CoPs consideram o conhecimento tácito e são compostas por entusiastas que voluntariamente querem aprender e pertencer a um grupo onde se partilham idéias. O sentimento de pertencer transmitido pelas comunidades de prática é um aspecto muito importante. Ele justifica a relevância dos artefatos de seus membros: rituais, linguagem, histórias etc. A duração e o estilo de gestão são as principais diferenças entre comunidades de prática e equipes de projeto.

Assim, quando se fala sobre prática, se está falando sobre prática social. Um conceito de prática inclui ambos, o explícito e o tácito. Inclui o que é dito e o que é não dito; o que é representado e o que é assumido. Inclui o idioma, as ferramentas, os documentos, as imagens, os símbolos, os papéis bem definidos, os critérios especificados, os procedimentos classificados, os regulamentos, e os contratos que várias práticas tornam adequados e explícitos para uma gama de propósitos. Mas também se incluem todas as relações implícitas, as convenções tácitas, as sugestões sutis, as regras não declaradas, as intuições reconhecíveis, as percepções específicas, as compreensões incorporadas, as suposições subjacentes, as visões de mundo compartilhadas que nunca puderam ser articuladas.

Entretanto esses são sinais inconfundíveis de sociedade em comunidades de prática e são cruciais para o sucesso dos seus empreendimentos. A estrutura emergente não pode ser separada do processo. Afirmar que é a aprendizagem que dá origem a comunidades de prática é dizer que a aprendizagem é fonte de uma estrutura social. Mas o tipo de estrutura ao qual se refere não é um objeto em si mesmo que pode ser separado do processo que lhe dá origem, antes é uma estrutura emergente (WENGER, 1996).

Brown e Duguid (2000), pesquisadores das Cops, as definem como sendo um grupo de indivíduos que trabalham juntos durante longo período e que, por terem compartilhado práticas, também compartilham experiências ricas. Além disso, 
elaboram seus próprios mecanismos de confiança, porque sabem o que cada um deles é capaz de fazer. Isso permite que, dentro da comunidade, as idéias fluam mais facilmente. Uma comunidade é um grupo de pessoas com interesses semelhantes e que se reúnem em determinado lugar (físico ou não) para discutir e partilhar conhecimento. Para que isto aconteça e, em conseqüência disto, são criados documentos, utilizadas ferramentas e são definidos valores (WENGER; LAVE, 2000).

De acordo com Stein (1998), através das CoPs os indivíduos interpretam, refletem e atribuem significados. Comunidade provê um setting de interação social necessária para engajarem-se no diálogo com outros, para poderem ver de várias perspectivas qualquer assunto (LAVE; WENGER 1991).

Comunidade é o link da prática com análise e reflexão para compartilhar as compreensões tácitas e criar conhecimento compartilhado a partir das experiências entre participantes numa oportunidade de aprendizagem. Também se recorre ao corpo de conhecimento criado pelo indivíduo que ingressa numa área de investigação. Jacobson (1996) identifica conhecimento prático e conhecimento cultural como comunidades em que um novo integrante tem que aprender, perceber, interpretar e comunicar experiência por interações com outros integrantes daquela comunidade. A Comunidade provê a oportunidade para a interação; a participação proporciona ao indivíduo o significado da experiência. Uma comunidade de prática é diferente de uma equipe, porque é definida por um tópico de interesse, não por uma tarefa que se tenha de realizar. É também diferente de uma rede informal, porque tem tópico, tem identidade (LAVE; WENGER, 1991; WENGER; SNYDER, 2001). Conforme estes autores, há três elementos na definição de comunidades de prática.

1. Um é o domínio: trata-se do tema sobre o qual a comunidade fala.

2. O segundo é a própria comunidade: as pessoas têm de interagir e construir relações entre si em torno do domínio. Uma página na web não é uma $\mathrm{CoP}$ ou, se houver sessenta gestores que nunca se falam, eles não são uma $C o P$, ainda que desempenhem as mesmas funções. Tem de existir como uma comunidade.

3. O terceiro é a prática: tem de existir uma prática e não apenas um interesse que as pessoas partilham. Elas aprendem juntas como fazer coisas pelas quais se interessam.

Embora os autores Wenger e Snyder (2001) percebam as comunidades de prática, os grupos de trabalho formais, as equipes e as redes informais como questões diferentes, eles entendem que elas são complementares. A seguir um resumo de suas características no Quadro 2. 


\section{Quadro 2: Resumo Comparativo das Características}

\begin{tabular}{|c|l|l|l|l|}
\cline { 2 - 5 } \multicolumn{1}{c|}{} & Qual é o Objetivo? & Quem Participa? & \multicolumn{1}{|c|}{$\begin{array}{c}\text { O que têm em } \\
\text { comum? }\end{array}$} & Quanto tempo duram? \\
\hline $\begin{array}{c}\text { Comunidade de } \\
\text { Prática }\end{array}$ & $\begin{array}{l}\text { Desenvolver as } \\
\text { competências dos } \\
\text { participantes; gerar e } \\
\text { trocar } \\
\text { conhecimentos }\end{array}$ & $\begin{array}{l}\text { Participantes auto- } \\
\text { selecionados }\end{array}$ & $\begin{array}{l}\text { Paixão, compromisso } \\
\text { e identificação com } \\
\text { os conhecimentos } \\
\text { especializados do } \\
\text { grupo }\end{array}$ & $\begin{array}{l}\text { Enquanto houver interesse } \\
\text { em manter o grupo }\end{array}$ \\
\hline $\begin{array}{c}\text { Grupo de } \\
\text { Trabalho Formal }\end{array}$ & $\begin{array}{l}\text { Desenvolver um } \\
\text { produto ou prestar } \\
\text { um serviço }\end{array}$ & $\begin{array}{l}\text { Qualquer um que } \\
\text { se apresente ao } \\
\text { gerente do grupo }\end{array}$ & $\begin{array}{l}\text { Requisitos do } \\
\text { trabalho e metas } \\
\text { comuns }\end{array}$ & $\begin{array}{l}\text { Até a próxima } \\
\text { reorganização }\end{array}$ \\
\hline Equipe de Projeto & $\begin{array}{l}\text { Realizar } \\
\text { determinada tarefa }\end{array}$ & $\begin{array}{l}\text { Empregados } \\
\text { escolhidos por } \\
\text { gerentes seniores }\end{array}$ & $\begin{array}{l}\text { As metas e pontos } \\
\text { importantes do } \\
\text { projeto }\end{array}$ & Até o final do projeto \\
\hline Rede Informal & $\begin{array}{l}\text { Colher e transmitir } \\
\text { informações } \\
\text { empresariais. }\end{array}$ & $\begin{array}{l}\text { Amigos e } \\
\text { conhecidos do } \\
\text { meio empresarial }\end{array}$ & Necessidades mútuas & $\begin{array}{l}\text { Enquanto as pessoas } \\
\text { tiverem um motivo para } \\
\text { manterem contato. }\end{array}$ \\
\hline
\end{tabular}

Fonte: Wenger e Snyder, 2001, p. 15.

Para finalizar, as empresas realizam muito de seu trabalho pensando em CoPs - especialmente nas sobreposições e alianças que reúnem as comunidades discrepantes. Entretanto, precisamente nestas sobreposições é que as competências essenciais vivem. A maioria das empresas comete o erro de definir competências como tecnologias distintas: patentes, negócios secretos, propriedade de design. Mas uma competência do mundo real — uma capacidade contínua para ultrapassar a competição — tem muito de si construída com know-how implícito e relações como produtos tangíveis e ferramentas. Não se pode divorciar as competências do tecido social que as apóia (BROWN; DUGUID, 2000).

\section{A Criação de Comunidades de Prática: Discutindo uma Concepção para os Cursos na Pós-graduação lato Sensu}

A literatura sobre aprendizagem informal e comunidades de prática e sua estreita relação com a aprendizagem na ação nortearão a discussão que aqui se iniciará: cursos de especialização em administração com uma concepção e organização voltada para criação de Comunidade de Prática.

A proposta aqui apresentada buscou referências em Raelin (1997), que propõe um modelo calcado na aprendizagem baseada no trabalho (work based learning). O modelo deste autor é postulado na simples idéia de que aprendizagem pode ser adquirida por meio da prática. Raelin propõe que sejam fundidas deliberadamente teoria e prática; ele reconhece a interseção de formas explícitas e tácitas de saber. De acordo com ele há oito modalidades de aprendizagem neste modelo. 
Sua proposta concentra-se em três estratégias de ação e são apresentadas como: aprendizagem na ação, ciência da ação e comunidades de prática.

Embora atualmente exista uma fonte rica de conhecimento para nos ajudar a entender como a aprendizagem baseada no trabalho ocorre e pode ser facilitada, precisamos de uma concepção que possa integrar as muitas tradições que estão por trás de sua construção (RAELIN, 1998). Ao aqui tentar desenvolver esta concepção, incorporaram-se duas dimensões fundamentais para o processo de aprendizagem na ação: teoria e modos de prática de aprender, e formas explícitas e tácitas de conhecimento.

Desde que a teoria possa ser vista como estrutura que desafia as suposições da prática, tem sentido combinar o modo de aprender com a ação. A conexão entre as intenções do professor e a compreensão dos estudantes é mais bem obtida pela ação. Praticar é o processo pelo qual os indivíduos adquirem e praticam seu aprendizado (SCHÖN, 1983).

Além da teoria e da prática, a outra dimensão incorporada foi a distinção entre formas explícitas e tácitas de conhecimento. Aprendizagem na ação requer uma epistemologia de prática que busca não somente explorar as instruções explícitas e diretrizes disponíveis no local de trabalho, mas também os processos tácitos invocados pessoalmente pelos gerentes, como eles resolvem os problemas de gerenciamento diário. Conhecimento explícito é a forma classificada familiar que é transmissível pela linguagem formal e sistemática. Conhecimento tácito é o componente de conhecimento que não é facilmente relatado, à medida que está profundamente vinculado à ação e implicado num contexto específico (POLANYI, 1983). Em outras palavras, embora os indivíduos possam ser educados no que eles fazem, eles não têm facilidade para descrever o que eles sabem (PLEASANTS, 1996).

Assim, há dois níveis de atividade nos quais se aprende pela ação e pelo trabalho. Um deles é que se pode aprender em nível individual, quando a interseção dos modos de aprendizagem e as formas de conhecimento desafia as estruturas pessoais de ação. Porém aprender numa extensão de aprendizagem que vá além da individual já diz respeito a outro nível, o da aprendizagem de nível coletivo. Este nível é constituído por colegas de trabalho, estejam eles presentes dentro ou fora da sua unidade de trabalho ou sala de aula, níveis estes que podem ser identificados nas comunidades de prática.

Os Quadros 3 e 4 exibem as matrizes que descrevem quatro tipos de aprendizagem do nível individual e quatro do nível coletivo. Devido às limitações em termos da abrangência deste artigo, não é possível desenvolver um tratamento 
teórico para cada um dos tipos apresentados, mas sim aportar ao leitor uma idéia do modelo em prática.

\section{Quadro 3: Um Modelo de Aprendizagem Baseada no Trabalho (Nível Individual)}

\begin{tabular}{|c|c|c|}
\hline MODOS DE & \multicolumn{2}{|c|}{ FORMAS DE CONHECIMENTO } \\
\hline APRENDIZAGEM & EXPLICITO & TACITO \\
\hline TEORIA & Conceituação & Experimentação \\
\hline PRÁTICA & Reflexão & Experiência \\
\hline
\end{tabular}

\section{Quadro 4: Um Modelo de Aprendizagem Baseada no Trabalho (Nível Coletivo)}

\begin{tabular}{|c|c|c|}
\hline MODOS DE & \multicolumn{2}{|c|}{ FORMAS DE CONHECIMENTO } \\
\hline APRENDIZAGEM & EXPLICITO & TACITO \\
\hline TEORIA & Ciência aplicada & Aprendizagem na ação \\
\hline PRÁTICA & Ciência da Ação & Comunidades de prática \\
\hline
\end{tabular}

Como se pode verificar, o modelo não tem nenhuma ordem de seqüência fixa, uma vez que as modalidades de aprendizagem dependem de muitas condições que não se podem definir a priori, tais como o nível de prontidão dos estudantes, as forças e preferências do facilitador e professor, ou as práticas transmitidas pela unidade de trabalho ou pela organização.

Desta forma, sugere-se que o curso se constitua de quatro grandes fases interrelacionadas (vide ilustração no final do artigo - Figura 1).

1) Fase Investigação: caracteriza-se mais por uma sondagem e reconhecimento do programa do curso e seus objetivos. O objetivo também é principalmente o de estabelecer um contrato de aprendizagem e o reconhecimento do valor da filosofia da aprendizagem na ação. Nesta fase preliminar os participantes adaptam-se e compreendem os objetivos do desenvolvimento de um projeto na prática com vistas à realização de um trabalho de conclusão de curso. Lançam as primeiras perguntas de investigação que serão discutidas com seu orientador e sua organização. Estabelecem um processo inicial de reflexão sobre a área de interesse na qual o projeto será desenvolvido - e que deve necessariamente resultar num trabalho de conclusão.

2) Fase de Exploração:é a mais significativa. Depende do ritmo do aluno e de seu planejamento, bem como do fluxo das disciplinas. Os alunos são auxiliados a explorar a provável área de estudo, avaliar sua experiência prévia, identificar um projeto satisfatório e preparar contrato de aprendizagem detalhado para seu programa de trabalho. Os participantes escolhem uma competência gerencial que entendam possa ser desenvolvida. Definem o foco do projeto e suas etapas. 
São subsidiados com conteúdos e experiências voltados para noção de aprendizagem, ação e competências gerenciais.

3) Fase de desenvolvimento:é a mais longa de todo o programa. Envolve os participantes, se necessário sua equipe no local de trabalho, o orientador e, ainda, se ele decidir, um mentor no local de trabalho. Os participantes apresentam um cronograma detalhado do desenvolvimento do projeto, bem como relatórios parciais, incluindo um diário de aprendizagem ${ }^{(3)}$ (que iniciou já na primeira fase). Terão oportunidade de experimentar novas teorias, colocando-as em prática e obter o suporte de uma equipe de aprendizagem (orientador, mentor e colegas e/ ou algum expert da empresa).

4) Fase da Demonstração:ocorre a preparação do material do projeto para avaliação final. Os participantes devem revisar como suas teorias eram aplicadas na prática e solicita-se que preparem um relatório que detalhe as aprendizagens e competências obtidas na experiência. Além disso, ocorre a apresentação formal das conclusões (trabalho final do curso) para colegas de aula, empresas ou mentor, orientador, e para outros executivos interessados, sinalizando as mudanças, competências desenvolvidas e aprendizagens adquiridas.

O programa avança gradativamente para um nível de atividade em que é solicitado aos participantes que pratiquem intencionalmente algumas de suas novas idéias. O modo de subsidiar este tipo de aprendizagem é o de trabalhar em grupos por projetos apoiados pela organização e na organização, associados ao trabalho de conclusão, e que podem representar qualquer problema em situações atuais ou oportunidades para melhoria.

Pode-se controlar a identificação de projetos, usando métodos convencionais da ciência aplicada e, para tanto, é imprescindível disciplina e orientação sobre métodos e técnicas de pesquisa. Os participantes podem trabalhar em projetos com um funcionamento individual ou como parte de uma equipe/grupo. Em ambos casos, eles podem complementar sua aprendizagem por encontrar-se em equipes de aprendizagem na ação, bem como um modo para ajudá-los a questionar sua experiência em tempo real (PEDLER, 1991). O plano e ações inclusos no projeto e trabalho de conclusão são avaliados em sua efetividade. 


\section{Figura 1}

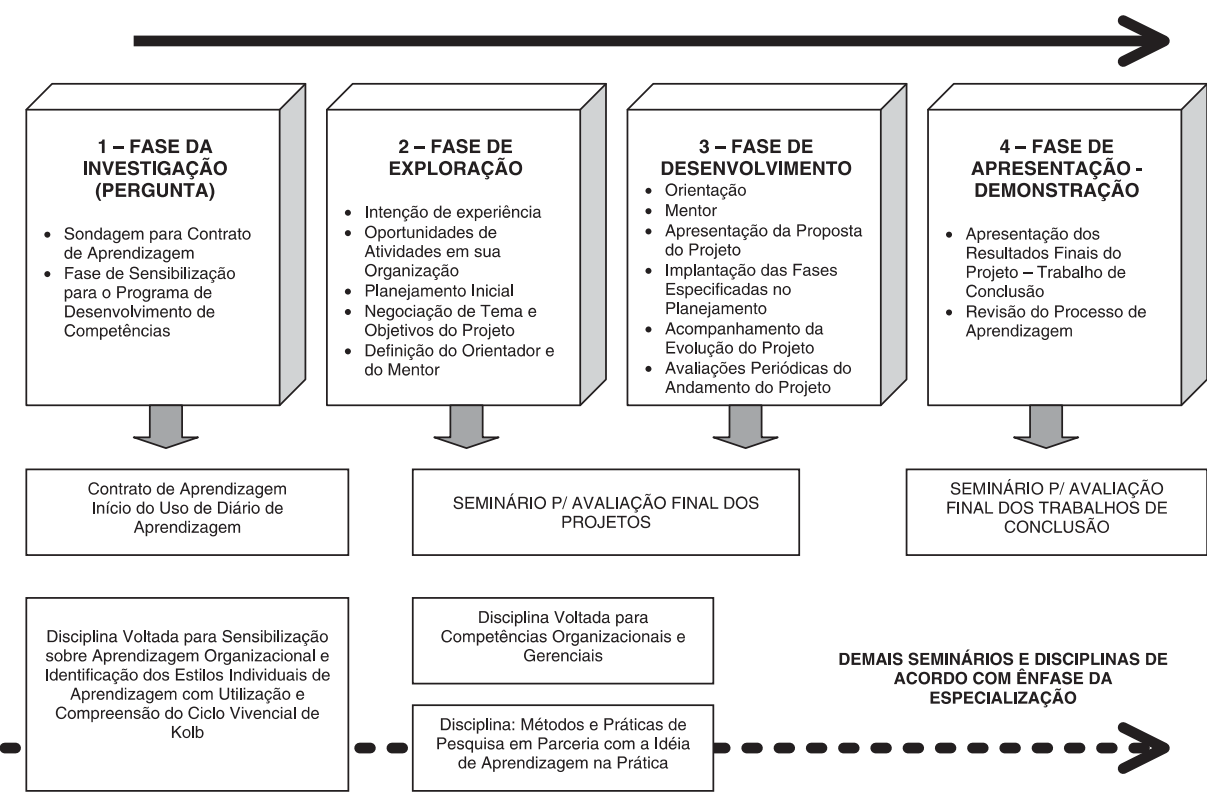

Tomando como parâmetro a literatura sobre o assunto, sugere-se que as disciplinas utilizem, como estratégias de aprendizagem e recursos didáticos, trabalhos em grupo, exercícios práticos, jogos de empresa, estudo de caso e simulações, pois estes facilitam a aprendizagem informal; compartilhamento de experiência, informações e conhecimento; bem como a socialização de seus participantes, criando assim ambiente para a geração de comunidades de prática.

Para explorar os aspecto da aprendizagem informal, as discussões podem evoluir do nível puramente conceitual à reflexões relativas ao uso das idéias na prática. Os participantes precisam ser encorajados a trazerem experiências de seu ambiente de trabalho, verificarem ou desafiarem algumas das teorias sob revisão, sejam vinculadas ao seu projeto ou em trabalhos desenvolvidos nas disciplinas. Durante o curso são incentivados a observarem a si próprios, aos demais na prática e a tentar se tornarem mais sensíveis ao como e por que seu desempenho ocorre de determinado modo. Em particular, devem tentar refletir que teorias tácitas realmente são utilizadas na prática, como estas teorias contrapõem-se às novas teorias introduzidas no programa e se as pessoas na verdade se comportam constantemente de acordo com as teorias a que aderem.

Pode ser difícil para alguns participantes se ocuparem dos componentes reflexivos descritos sem a ajuda de um colega e/ou um mentor. Estes papéis de 
mentores podem ser críticos para os participantes experimentarem novos comportamentos no local de trabalho e aprenderem com suas experiências. Podem ser utilizados três papéis de mentor, segundo Burnside e Guthrie (1992):

a) de conselheiro de processo, representado por um profissional de RH que reúne os participantes pessoalmente e por telefone durante a experiência do curso;

b) colegas do curso que trabalham um com outro no sentido de experimentar e refletir sobre as experiências de sala de aula;

c) pares na organização que ajudam os participantes a transferirem aprendizagens para o local de trabalho.

Como foi dito, a aprendizagem informal resulta diretamente de atividades relacionadas com o trabalho e se dá nos interstícios e espaços da vida organizacional. Ao sugerir esta concepção de formação está-se intercambiando com o ambiente de ensino um pouco destes espaços. A relação e interação interpessoal em processos sociais básicos, sugeridos para o curso, tais como: resolução de problema formal e informal em grupos; desenvolvimento de projetos; a reflexão na experiência; a aplicação da aprendizagem em prática; a realização do confronto dos gaps entre as atividades profissionais e a realidade; em suma, a possibilidade de aprender com colegas culmina ou no mínimo favorece o surgimento ou criação de uma comunidade de prática.

Considera-se que a abordagem da aprendizagem na ação (RAELIN, 1997) oferece uma epistemologia que, ao ser integrada aos domínios de programas de especialização, pode ser útil na concepção destes programas, isto porque auxilia os gerentes a atribuírem significado à experiência, a elevar a sua consciência da sua teoria-em-uso e a desenvolver, testar e continuamente refinar teorias subjetivas de ação, facilitando a sua formação e, portanto, o desenvolvimento de suas competências.

Pode-se também denominar esta abordagem como orientada a problemas, uma vez que seu ponto de partida é o encontro do indivíduo com o problema que o faz parar e pensar e o leva, por meio de uma indagação calculada, a refletir, pensar e mudar sua prática ou não. Em outras palavras, o indivíduo, ao descobrir um problema, levanta indagações, reflete e o soluciona. Entretanto todo o processo se insere numa prática social originada do trabalho em grupo, o que significa que a aprendizagem envolve mudanças tanto na prática social como em indivíduos engajados em uma contínua reorganização e reconstrução de sua experiência. Eles precisam estar empenhados em processos de crescimento pessoal, assim como em mudanças sociais na forma de câmbios organizacionais.

A participação pode ser descrita como um elemento fundamental no processo 
de aprendizagem. Trata-se do processo pelo qual os estudantes que trabalham em conjunto e com experts numa organização social, resolvendo problemas relacionados a circunstâncias de sua vida cotidiana (BROWN; DUGUID, 1992). Esta participação descreve o intercâmbio de idéias, a tentativa de resolver problemas e o compromisso ativo dos indivíduos entre si e com os conteúdos de aprendizagem. É o processo de interação com outros que produz e estabelece sistemas de significado entre os aprendizes. A partir de uma perspectiva de cognição situada, a aprendizagem ocorre num setting (cenário/espaço) social através do diálogo com outros na comunidade. Aprender se torna um processo de refletir, interpretar e negociar significados entre os participantes de uma comunidade. Aprender é compartilhar as narrativas produzidas por um grupo de estudantes (STEIN, 1998).

Finalmente, o último ponto a realçar: trata-se da relação das comunidades de prática com o desenvolvimento de competências. "Competência gerencial é a capacidade de mobilizar, integrar e colocar em ação conhecimentos, habilidades e atributos, a fim de atingir/superar desempenhos configurados nas atribuições” (RUAS, 2002). Parte-se da noção de que a competência não é um estado nem um saber que se possui, nem uma aquisição de formação. Ela só é compreensível - e suscetível de ser produzida - “na ação”. Daí seu caráter finalizado, contextual e contingente.

Neste sentido é que as competências são emergentes dos contextos da ação gerencial (e não prévias). Significa que a produção de competências supõe uma situação de comunicação e de aprendizagem: a competência do gerente é fruto de uma nova combinação, obtida por confrontação com outros tipos de 'saberfazer'. Não é possível haver competência na ausência de interação e transação (BOTERF, 1999). A Comunidade de Prática é ambiente propício para o desenvolvimento de competências, por disponibilizar espaço e contexto de interação, trocas, ação e práticas. Além disso, os conhecimento e competências, quando adquiridos em ambiente sociais concretos, normalmente ocorrem em CoPs, ou seja, não se podem dissociar as competências do tecido social que as apóia, como disseram Brown e Duguid (1999, 2000).

\section{Considerações Finais}

A evolução recente nas teorias das organizações, bem como nos princípios e práticas de gestão, constitui um contexto favorável à busca de novos modelos e estratégias de aprendizagem nas organizações e nos programas de formação 
gerencial. Observa-se cada vez mais uma integração do campo da formação com o campo da organização, o que leva a uma articulação das situações de aprendizagem com as situações de trabalho. Uma das perspectivas que mais tem favorecido esta integração é a que encara a formação como investimento produtivo, integrada à decisão política e à estratégia geral da organização.

Desta forma, os planos de formação e desenvolvimento tendem a articular-se estreitamente com o plano estratégico da empresa. Entretanto, mesmo associados a uma dimensão estratégica, precisam assumir formas concretas como, por exemplo, iniciativas para resolução de problemas ou para desenvolvimento de novos projetos e, por que não, de comunidades de prática, como este artigo propõe.

A concepção de curso, aqui sugerida, integra simultaneamente as dimensões formação, investigação e ação. Esta e outras modalidades de formação que se desenvolvem no interior das próprias organizações, ainda que não confinadas aos seus espaços e aos saberes, como é o caso das comunidades de prática, constituem claro exemplo da emergência de novos paradigmas no campo da aprendizagem gerencial e organizacional, com pontos de contato com o que se passou no estudo das organizações e gestão.

Também é neste contexto, considerando a dimensão da aprendizagem organizacional e a formação de competências, que se valorizam cada vez mais as modalidades que favorecem a capacidade dos indivíduos nas organizações a produzirem seu próprio conhecimento, seja através dos métodos autobiográficos e formação experiencial, seja através da aprendizagem na ação informal, por projetos, histórias de aprendizagem e outros modelos de auto-formação.

A ação gerencial tem lugar em ambientes sociais, marcados pela singularidade e incerteza em que se cruzam objetivos organizacionais, a procura social e os próprios interesses dos indivíduos. A aquisição de um conjunto de saberes, a interiorização de um conjunto de valores e o domínio de um conjunto de gestos técnicos não se trata de pré-requisitos simples e linearmente transferíveis, determinando a ação gerencial. Os saberes anteriormente adquiridos constituem um estoque de recursos que podem ser mobilizados segundo modalidades e configurações muito diversas. É isto que explica o fato de que o conhecimento e o saber prévio ao exercício gerencial (ou como alguns denominam, qualificação), não garantem a competência. A apropriação da noção de $C o P$ como concepção para programas de ensino em administração, especialmente pós-graduação lato sensu, é uma tentativa de articular formação gerencial, aprendizagem em ação e desenvolvimento de competências gerenciais. 
Já a comunidade de prática não é um conceito novo, mas assumiu recentemente especial importância. Algumas organizações estão empenhadas em lhe atribuir um papel mais central e de adotar uma abordagem intencional relativa à sua criação. A justificativa para isto reside na crença de que o conhecimento é um ato de participação e que são aqueles que o produzem e o usam no dia-a-dia que o deveriam gerir. Um sistema social de aprendizagem é composto por várias comunidades de prática e também pelas relações e interações entre elas.

Assim, uma alternativa importante para a construção de um sistema social de aprendizagem pode passar por uma etapa preliminar de desenvolver comunidades e, depois disso, ajudá-las a aperfeiçoar as suas ligações. Para desenvolver comunidades de prática há três aspectos que considerar: a criação de um sentido de empreendimento comum, a renovação do compromisso mútuo, e o desenvolvimento de um repertório partilhado de conceitos, ferramentas, linguagem e histórias. Entende-se que o curso de pós-graduação lato sensu em administração, sem deixar de ser uma oportunidade de desenvolvimento gerencial formalmente projetada, poderá dar excelentes contribuições na árdua tarefa de tecer estas 'teias de participação' - Cops - contemplando ainda a articulação entre a aprendizagem formal e informal.

O tema é instigante e nos oferece algumas indagações para reflexão, entre elas: quais os riscos da organização interferir e buscar o controle de processos informais de aprendizagem e assim 'sufocá-los'? Há infra-estrutura e condições para que professores, orientadores e mentores estejam engajados e articulados entre si para realização de um tipo de trabalho que exige esta concepção de curso? Quais seriam os resultados desta concepção de programa em cursos que não o in company? Ficam estas e possivelmente outras questões levantadas pelo próprio leitor para futuros debates.

\section{Artigo recebido em 01.11.2003. Aprovado em 09.11.2004.}

\section{Notas}

\footnotetext{
${ }^{1}$ Ou seja, orientados objetivamente para um segmento produtivo ou para uma empresa e restritos a profissionais deste meio

2 Teoria da Aprendizagem Situada é uma idéia proposta por Jean Lave (1991). Este autor argumenta que o aprendizado sempre ocorre em função da atividade, contexto e cultura no qual ocorre ou se situa. Esta proposição contrasta com a maioria das atividades de sala de aula, que envolvem conhecimentos abstratos, totalmente descontextualizados de situações concretas. A
} 
interação social é um componente crítico do aprendizado situacional; nele, os aprendizes ficam envolvidos em Comunidades de Prática, que portam certas convicções e definem comportamentos a serem adquiridos. Na medida em que os novatos ou recém chegados se movem da periferia destas comunidades para o centro, eles se tornam mais ativos e engajados na construção da cultura destas. A partir daí, assumem o papel de experts, tornando-se referências do meio. Nesse sentido, o aprendizado ocorre de maneira não intencional, não deliberada.

${ }^{3} \mathrm{Um}$ instrumento complementar para ajudar os participantes a refletirem mais sobre seu desenvolvimento individual é o diário. Escrever um diário propicia uma oportunidade para os alunos romperem com seus modos habituais de pensar e fazer, através da reflexão (LUKINSKY, 1990). Os diários ajudam aos participantes a filtrar lições de experiência e os ajudam a localizar sua aprendizagem, sejam de lições importantes, tendências ou padrões (CELL, 1984). O diário ou diário de bordo ou ainda diário de aprendizagem, propicia e incentiva a disciplina aos participantes para refletirem sistematicamente sobre suas experiências.

\section{ReferênCias Bibliográficas}

\section{BJORNAVOLD, J.}

La visualización del aprendizaje: detección, evaluación y reconocimiento de los aprendizajes no formales. Revista Europea de la Formación Profesional, n. 22, 2001. Disponível em: <http:// prometeo.cica.es/recursos/catalogo/ forapr.htm>. Acesso em: 28 ago. 2002.

BOLAND, R. J.;

\section{TENKASI, R. V.}

Perspective making and perspective taking in communities of knowing, Organization Science, Linthicum, v. 4, n. 6, p. 350-72, july/aug. 1995.

\section{BOLT, J.}

Achieving the CEO's agenda: education for executives. Management Review. New York, p. 44-48, 1993.

\section{BOTERF, G.}

L'ingénierie des compétences. 2. ed. Paris: Les éditions d'organisation, 1999. p. 544.
BROWN, J.S.;

DUGUID, $P$.

Organizational learning and communities-of-practice: Toward a unified view of working, learning and innovation. Organization Science, Linthicum, v. 2, n.1, p. 40-57, 1999.

When change is constant, maybe we need to change our own eyeglasses. Trabalho apresentado no Learning in Organizations Workshop, University of Western Ontario Business School. London, p. 21-23, june 1992.

The Social Life of Information. Boston: Harvard Businesses School Press, 2000, p.319.

\section{BURGOYNE, J.;}

STUART, R.

Teaching and learning methods in management development. Personnel Review, v. 20, n. 3, p. 27-33, 1991. 
BURNSIDE, R. M.;

GUTHRIE, V.A.

Training for Action: a new approach to executive development. 1 . ed. Greensboro: Center for Creative Leadership. 1992.

\section{BUSINESS WEEK.}

The Best B schools, New York, p. 6270, 1994.

\section{CELL,E.}

Learning to Learn from Experience, 1. ed. New York : University of New York, 1984.

\section{DIONNE P.}

The Evolution of Training activities. Human Resource Development Quarterly, São Francisco, v. 7, n. 3, p. 279-86, 1996.

\section{DOYLE, $M$.}

Organisational transformation and renewal: a case for reframing management development? Personnel Review, Farnborough, v. 24, n. 6, p. 6-18, 1994.

\section{ELLER,D.}

Motorola trains VPs to become growth leaders, HR Magazine. Virginia - USA, june 1995. Disponível em: http://www.findarticles.com/p/ articles/mi_m3495/is_n6_v40. Acesso em: 30 mar. 2001.

GHOSHAL, S;

ARNZEN, B;

BROWNFIELD, A.

A learning alliance between business and business schools: executive education as a platform for partnership, California Management Review, Berkeley, v. 35, p. 50-67, fall 1992.
HEQUET, $M$.

Executive education: the custom alternative. Training. Minneapolis, v. 29. n. 4, p. 38-41, apr. 1992.

\section{JACOBSON, W.}

Learning, culture and learning culture. Adult Education Quarterly. Georgia, v. 47, n 1, p. 15-28, 1996.

\section{KEYS,L.}

Action Learning: executive development of choice for the 1990s. Journal of Management Development, Bradford, v. 13, n. 8, p. 50-6, 1994.

\section{LANKARD, B A.}

Source: C Clearinghouse on Adult Career and Vocational Education Columbus OH. ERIC Digest, n. 161, 2000. Disponível em: <http:// w w w.e d.gov/d a t a b a s e s / ERIC_Digests/ed385778.html.>. Acesso em: 20 mar. 2001.

\section{LAVE, J.;}

WENGER, E.

Situated learning: legitimate peripheral participation. Cambridge: Cambridge University Press, 1991.

\section{LIEDTKA J.;}

WEBER C.;

WEBERJ.

Creating a significant and sustainable executive education experience. Journal of Managerial Psychology. Bradford, v. 14, n. 5, p. 404-420, 1999.

LEWIS, A.;

MARCH, W.

Action learning: the development of field managers in the Prudential Insurance Company. The Journal of Management Development, Bradford, v. 6, n. 2, p. 45-57, 1987. 
LIVINGSTONE, D.

Exploring the icebergs of adult learning: Findings of the first Canadian survey of informal learning practices. Canadian Journal for the Study of Adult Education. Toronto, v. 3, n. 2, p. 49-72, 1999.

\section{LORANGE, P.}

Back to scholl: executive education in the US, Chief Executive. New York, p. 36-9, mar. 1994.

\section{LUKINSKY, J.}

Reflective withdrawal through journal writing. In: MEZIROW, J. et al. (Org.) Fostering Critical Reflection in Adulthood. San Francisco: Jossey Bass, p. 213-234, 1990.

\section{MCCLENAHEN, J.}

Custom Designs. Information World. Oxford, p. 37-41, jan. 1996.

\section{MERALI, Y.}

Communities of practice in knowledge management. Intelligence in Industry. United Kingdom, n. 3, p. 9-13, mar./apr. 2000.

OREY, M.A.;

NELSON, W. A.

Situated Learning and the Limits of Applying the Results of These Data to the Theories of Cognitive Apprenticeships. In: National Convention of the Association for Educational Communications and Technology, Washington, fev. 1994. p. 16-20.

\section{PEDLER, $M$.}

Action Learning in Practice, 2 ed. Gower: Aldershot, 1991.

\section{PLEASANTS, $\mathrm{N}$.}

Nothing is concealed: de cent ring tacit knowledge and rules from social theory, Journal for the Theory of Social Behaviour, New York, v. 26, n. 3, p. 233-55, 1996.

\section{POLANY, M.}

The Tacit Dimension, 2. ed. New York: Doubleday, 1983. p. 99.

\section{RAELIN. J.}

A model of work-based learning. Organization Science, Linthicum, v. 8, n. 6, p. 563-78, 1997.

Learning and Doing. HR Magazine, Virginia-USA, v. 38, n. 2, p. 61-70, 1993.

Work based learning in practice, Journal of Workplace Learning, Bradford, v. 10, n. 6-7, p. 280-283, 1998.

REVANS, R. W.

Developing Effective Managers, 1. ed. Longmans:London, 1971 p. 254.

The origins and development of action learning. 1. ed. London: Brookfield Publishing, 1982. p. 211.

\section{RIFKEN, G.}

Leadership - can it be learned? Forbes, 1. ed. New York p. 100-12, apr. 1996.

\section{SCHÖN, D.}

The Reflective Practitioner: how professionals think in action, 1. ed. New York: Basic Books, 1983. p. 374. 
SCHUGURENSKY,D.

The forms of informal learning. New Approaches to Lifelong Learning Conference. Toronto, oct. 2000. Disponível em: <http:// f c i s.o is e.utoron to.ca/ \%7Edaniel_schugurensky>. Acesso em: 17 apr. 2001.

STEIN, D.

Situated Learning in Adult Education. OERI or the Department. ERIC Digest, n. 178. Disponível em: $<$ http://ericacve.org/docs/ situated195.htm.>. Acesso em: 15 mar. 2001.

\section{RUAS, R.}

Mestrado Executivo, Formação Gerencial e a Noção de Competências: provocações e desafios. In: ENCONTRO ANUAL DAANPAD, 25., 2001, Campinas. Anais... Campinas: ANPAD, 2001a.

\section{A Gestão das Competências Gerenciais e a Aprendizagem nas Organizações. PPGA/UFRGS, Porto Alegre, 2001b. p. 32.}

Aprendizagem nas Organizações e Desenvolvimento de Competências. Porto Alegre: PPGA/UFRGS. Mimeo. 2002.

TANNENBAUM, S.;

WOODS, S.

Determining a strategy for evaluating, training, operating within organizational constraints, Human Resources Planning, New York, v.15, n. 2, p. 63-81. 1992.
THE JOURNAL OF BUSINESS STRATEGY.

Class of 96: pragmatic courses for trying times; Boston; mar./apr, 1996. p. 37-41.

VICERE, A. A.;

WHITE, A. F.

Towards a systems approach to executive development The Journal of Management Development, Bradford, v. 13, n. 5, p. 64-72, 1994.

WATKINS, K. E.;

MARSICK, V. J.

Toward a Theory of Informal and Incidental Learning in Organizations. International Journal of Lifelong Education, Guidford-UK, v. 11, n. 4, p. 287-300, oct./dec. 1992.

\section{WENGER, E.}

Communities of practice: The social fabric of a learning organization. Healthcare Forum Journal, San Francisco, v. 39, n. 4, p. 20-26, july/aug. 1996.

Communities of practice: learning as a social system. Trabalho apresentado em Toronto, abril, 1999.

\section{WENGER, E;}

LAVE, J.

Knowledge and Communities. In: LESSER, E. L.; FONTAINE, M A.; SLUSHER, JA(Ed.), Communities of practice: the key to knowledge strategy. 1. ed. USA: ButterworthHeinemann. 2000. p. 272. 
Communities of Practice: learning, meaning, and identity. 1. ed. Cambridge: Cambridge University Press, 1998. p. 318

\section{WENGER, E;}

SNYDER, W. M.

Comunidades de Prática: a fronteira organizacional. In, Aprendizagem Organizacional: organizational learning. 1. ed. Harvard Business Review, São Paulo: Campus, 2001. p. 9-26. 